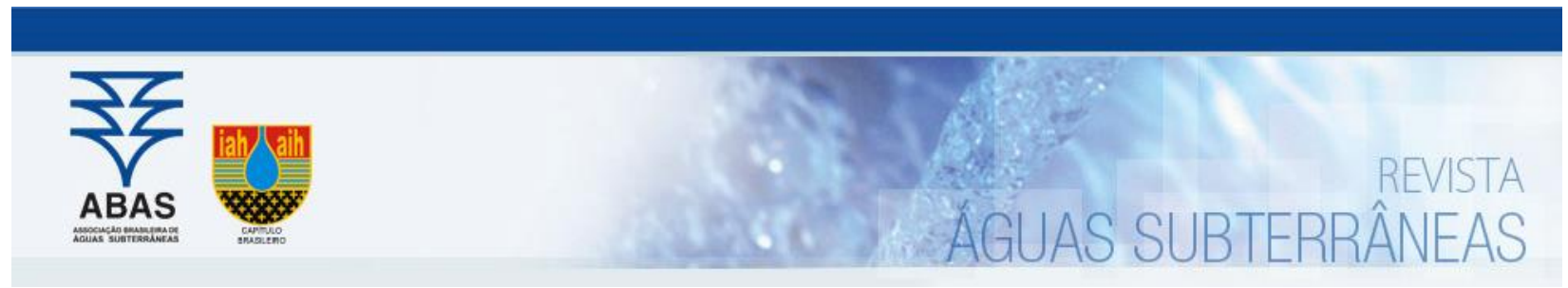

Artigos

\title{
Método de resistividade capacitiva e reclassificação dos métodos geoelétricos para estudos hidrogeológicos e de contaminação subterrânea
}

\section{Capacitive resistivity method and reclassification of geoelectric methods for hydrogeological and underground contamination studies}

\author{
Wagner Aquino1; Márcio Corrêa2; Paulo Tonello1 ${ }^{\circledR}$ \\ 1 Universidade Estadual Paulista (UNESP), Campus Sorocaba, SP \\ 2 Geométodos Levantamentos Geofísicos Ltda, São Paulo, SP
}

$\triangle$ wagnergpr@gmail.com, marcio@geometodos.com.br, paulo.tonello@unesp.br

\section{Palavras-chave:}

Resistividade Capacitiva; Reclassificação dos métodos geoelétricos.

Keywords:

Capacitive Resistivity;

Reclassification of geoelectric methods.

Revisão por pares

Recebido em: 22/09/2021.

Aprovado em: 29/10/2021.
Resumo

Este artigo apresenta os fundamentos teóricos do método geofísico de Resistividade Capacitiva, aplicado, mais recentemente, em investigações geológicas e de diagnósticos ambientais, com o objetivo de inseri-lo dentro da classificação estabelecida para os métodos geoelétricos e que tem servido como referência aos diversos textos técnicos e artigos acadêmicos nos últimos anos. Em função desta inclusão, foi imprescindível a execução de readequações na classificação existente, bem como modificações necessárias à sua atualização. A partir dessas alterações, é proposta uma nova reclassificação dos métodos geoelétricos baseada na estrutura fundamental já estabelecida, porém mais aberta às possibilidades de surgimento de novas tecnologias e mais adequada aos métodos geofísicos aplicados à investigação da contaminação subterrânea e que trabalham com a propriedade física de resistividade ou condutividade elétrica. Além disso, no transcorrer das discussões apresentadas, são reportadas algumas sinonímias que já vem sendo empregadas em memoriais técnicos ou trabalhos acadêmicos, e que devem ser divulgadas para plena ciência daqueles que atuam na área de Geofísica Aplicada e Ambiental, bem como efetuadas traduções de alguns termos técnicos para a língua portuguesa na reclassificação aqui proposta.

Abstract

This article presents the theoretical foundations of the Capacitive Resistivity geophysical method, applied, more recently, in geological investigations and environmental diagnostics, with the objective of inserting it within the classification established for the geoelectric methods and which has served as a reference to the different technical texts and academic articles in recent years. Due to this inclusion, it was essential to carry out readjustments in the existing classification, as well as necessary changes to update it. From these changes, a new reclassification of geoelectric methods is proposed based on the fundamental structure already established, but more open to the possibilities of the emergence of new technologies and more appropriate to the geophysical methods applied to the investigation of underground contamination and that work with electrical resistivity or conductivity. In addition, in the course of the discussions presented, some synonyms are reported that have already been used in technical memorials or academic works, and which should be disclosed to the full knowledge of those who work in the area of Applied and Environmental Geophysics, as well as translations of some technical terms for the Portuguese language in the reclassification proposed here.

DOI: http:/doi.org/10.14295/ras.v35i3.30076

\section{INTRODUÇÃO}

Este artigo foi elaborado em face da necessidade surgida mais recentemente relacionada à inclusão de nova metodologia geofísica, que é a Resistividade Capacitiva (RC), dentro da classificação dos métodos geoelétricos aplicados à hidrogeologia, definida por Braga (2006), uma vez que esse método indireto de investigação de subsuperfície já vem sendo em- pregado por alguns pesquisadores, casos de Cavenaghi (2017), Silva (2018) e Carmona et al. (2018).

Para é isso é fundamental rever os conceitos referentes aos métodos geofísicos de maneira geral e, em particular, àqueles da Geofísica Aplicada e à Geofísica Ambiental, os quais se baseiam nas definições consolidadas de alguns especialistas de grande importância nestas áreas específicas de atuação, cu- 
jos trabalhos, resultados e contribuições já foram reportadas em diversas publicações técnicas.

De maneira geral, quando se trata do emprego da Geofísica voltada para a investigação de um determinado meio, é necessário que haja correspondência entre a propriedade física do alvo de interesse com a adequada metodologia a ser aplicada e, que, se refere, assim, a utilização de um método geofísico específico e que também possua a capacidade de detecção de variações em suas medições (PARASNIS, 1997).

Neste sentido, conforme definido por Reynolds (2011), os métodos geofísicos se constituem em metodologias indiretas de investigação subterrânea, a partir da aquisição de dados instrumentais em superfície, caracterizando-se, portanto, como métodos não invasivos ou não destrutivos, permitindo, assim, avaliar as condições geológicas locais através dos contrastes das diferentes propriedades físicas dos materiais de subsuperfície, por exemplo condutividade ou resistividade elétrica, permissividade dielétrica, magnetismo, densidade etc., e que podem ter como origem as heterogeneidades litológicas e outras alterações naturais ou não.

Destaca-se aqui que, como descrito por Parasnis (1997) e também por Reynolds (2011), os métodos geofísicos se dividem, de maneira geral, em duas grandes classes de acordo com a natureza da fonte do sinal a ser medido: métodos passivos e métodos ativos.

Para esses autores, os métodos geofísicos passivos, ou estáticos, são aqueles que medem, através de dispositivos receptores, as variações que determinadas estruturas ou corpos em subsuperfície produzem sobre os campos naturais decorrentes de suas propriedades intrínsecas, podendo ser citados os métodos gravimétricos, de fluxo térmico e magnéticos, associados, respectivamente, à densidade, à temperatura e ao magnetismo.

Definem, também, os métodos geofísicos ativos, ou dinâmicos, como aqueles que se utilizam de fontes artificiais que transmitem o sinal para subsuperfície, detectando seu retorno e medindo os efeitos como resposta aos materiais presentes em profundidade, por exemplo o método de Sísmica de Refração e o método de GPR (Ground Penetrating Radar), nesta ordem, relacionados à geração de ondas sísmicas e emissão de ondas eletromagnéticas.

Em função dessas características, usualmente, os métodos geofísicos passivos podem fornecer maiores profundidades de investigação, porém apresentam um menor detalhamento (resolução) que os métodos geofísicos ativos, os quais permitem uma maior capacidade de definição dos alvos por ter fonte controlada do sinal emitido (PARASNIS, 1997).
Especificamente, a Geofísica Aplicada é definida por Reynolds (2011) como sendo a área da Geofísica que investiga os recursos minerais ou estruturas geológicas, relativamente pequenas e pouco profundas que possam estar presentes na crosta terrestre, sendo subdivididas, primordialmente, em três grupos maiores que são a Geofísica de Exploração, Geofísica de Engenharia e Geofísica Ambiental, além de outros grupos menores.

Neste contexto, para Greenhouse (1991) e Steeples (1991), a Geofísica Ambiental se refere à aplicação dos métodos geofísicos ao diagnóstico dos impactos causados ao meio físico, subdividida em dois campos da seguinte forma: utilizada em estudos de eventos de degradação, tais como avaliação de processos erosivos ou assoreamentos de corpos d’água, e num segundo objetivo mais voltado particularmente à investigação dos efeitos negativos provocados pela contaminação subterrânea.

Em relação às aplicações da Geofísica Ambiental na avaliação da contaminação do solo e da água subterrânea, destacamse os métodos geofísicos que operam com as propriedades elétricas como os mais eficientes e capazes de detectar suas variações quando da existência de contaminantes em subsuperfície, podendo ser citados a Eletrorresistividade, o Eletromagnético Indutivo, o GPR (ou Georadar), e, o método mais recente, que é a Resistividade Capacitiva (SILVA, 2018).

\section{MÉTODO DE RESISTIVIDADE CAPACITIVA}

De acordo com Kuras (2002), a metodologia geofísica de Resistividade Capacitiva (RC), também designada como método Resistivo-Capacitivo por Carmona et al. (2018), possui os princípios físicos do método de Eletrorresistividade e sua técnica de aquisição de dados, é similar, a princípio, ao caminhamento elétrico com arranjo dipolo-dipolo, sendo denominada de imageamento de resistividade capacitiva (capacitive resistivity imaging), porém, seu diferencial está nas características da fonte de emissão de corrente elétrica $(I)$ para subsuperfície através de um cabo coaxial contendo um transmissor de corrente elétrica alternada em contato com o terreno e na forma de recepção da tensão elétrica $(\Delta V)$ por um ou mais receptores sobre o solo, formando, portanto, um sistema capacitivo.

Na execução da técnica do imageamento de resistividade capacitiva (IRC), segundo Kuras (2002), tanto o transmissor de corrente elétrica, como o receptor de tensão atuam como dipolos individuais, constituindo assim um arranjo dipolo-dipolo, com cabos capacitivos transmissor e receptor posicionados numa forma alinhada à direção do perfil a ser executado, atuando como linha de antenas (Figura 1). 
Figura 1 - Corrente e potenciais elétricos nos dipolos capacitivos

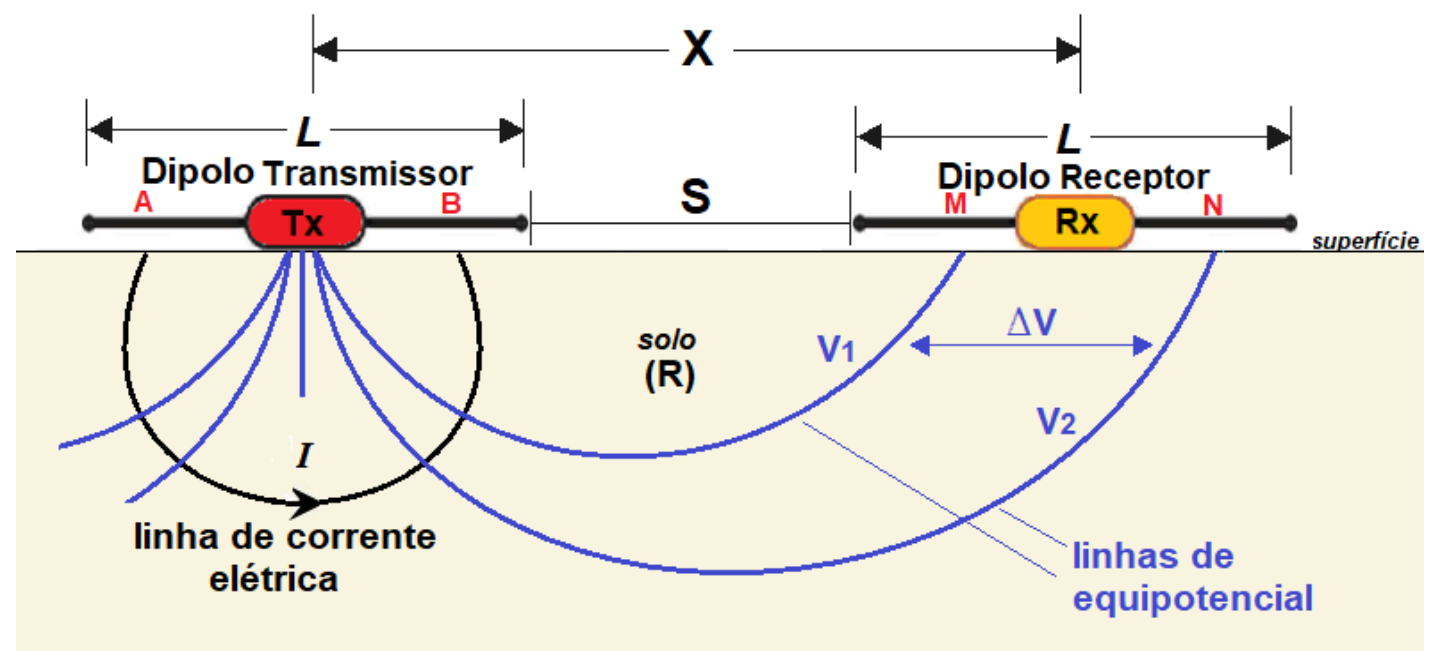

Fonte: os autores.

Assim, a resistividade aparente é calculada pela equação $\rho_{a}=K_{L A} \cdot \frac{\Delta V}{I}$, sendo $K_{L A}$ o fator geométrico do arranjo dipoloe o parâmetro $b=\frac{2 X}{L}$. dipolo capacitivo e será dado por:

$K_{L A}=\frac{\pi L}{\ln \left[\left(\frac{b^{2}}{b^{2}-1}\right)^{2 b}\left(\frac{b^{2}+2 b}{(b+1)^{2}}\right)^{b+2}\left(\frac{b^{2}-2 b}{(b-1)^{2}}\right)^{b-2}\right]}$,

onde $X$ é a separação entre os eletrodos capacitivos transmissor e o receptor, $L$ é o comprimento desses (Figura 1)

Segundo Yamashita et al. (2004), o sistema de acoplamento capacitivo provoca a passagem de corrente alternada através de um cabo coaxial que age como uma placa capacitora enquanto a superfície do solo age como a outra placa capacitora, sendo este acoplamento capacitivo de cabo-terra caracterizado por uma capacitância elétrica variável e que depende das condições de resistência $(R)$ do terreno (Figura 2).

Figura 2 - Circuito elétrico capacitivo para injeção de corrente no solo e recepção
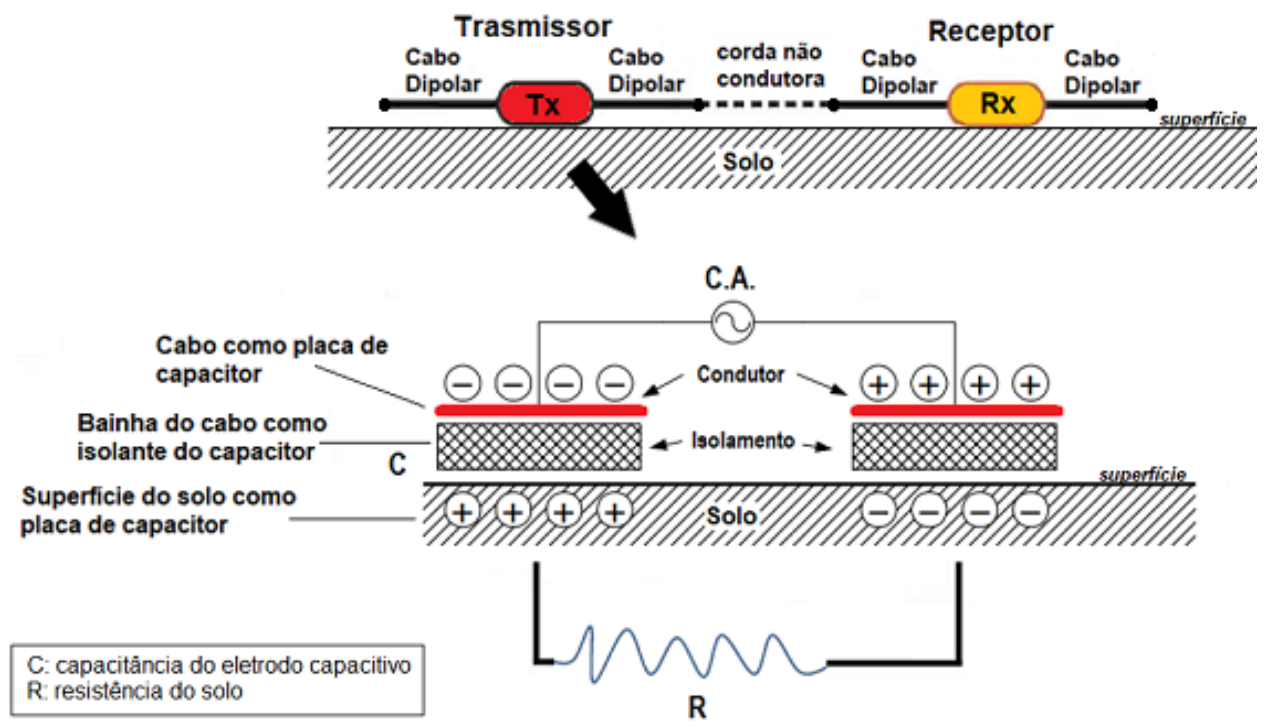

Fonte: adaptado de Yamashita et al. (2004) 
Desta forma, é transmitida uma corrente alternada (CA), numa frequência de sinal igual a $16,5 \mathrm{kHz}$, e que passará pelo cabo capacitor (transmissor) para o solo, carregando-o eletricamente por indução e não por contato, sendo a tensão medida nos receptores graças a sincronização em torno da frequência do sinal transmitido. Após a injeção de corrente de forma capacitiva, o nível de tensão recebido é convertido num sinal digital no receptor, sendo transferido para o registrador de dados para armazenamento e, posterior, conversão interna em valores de resistividade elétrica (KURAS, 2002). $\mathrm{Na}$ técnica de imageamento de resistividade capacitiva (IRC), a investigação das variações laterais da subsuperfície se rea- liza em níveis de profundidades diferentes ao longo de um perfil, constituindo-se numa varredura lateral da área de interesse, com intuito de se investigar a continuidade das feições ou estruturas em subsuperfície (REYNOLDS, 2011).

Assim, quando utilizado o equipamento Ohmmapper, marca Geometrics Inc (Figura 3) para a execução do imageamento elétrico com apenas um receptor de sinal (sistema monorreceptor), é necessário se repetir mais vezes o mesmo perfil, com separações sucessivamente maiores entre o transmissor (fonte do sinal) e o único receptor para possibilitar amostragens de porções geológicas gradativamente mais profundas (Figura 4).

Figura 3 - Componentes do sistema capacitivo Ohmmapper da Geometrics Inc

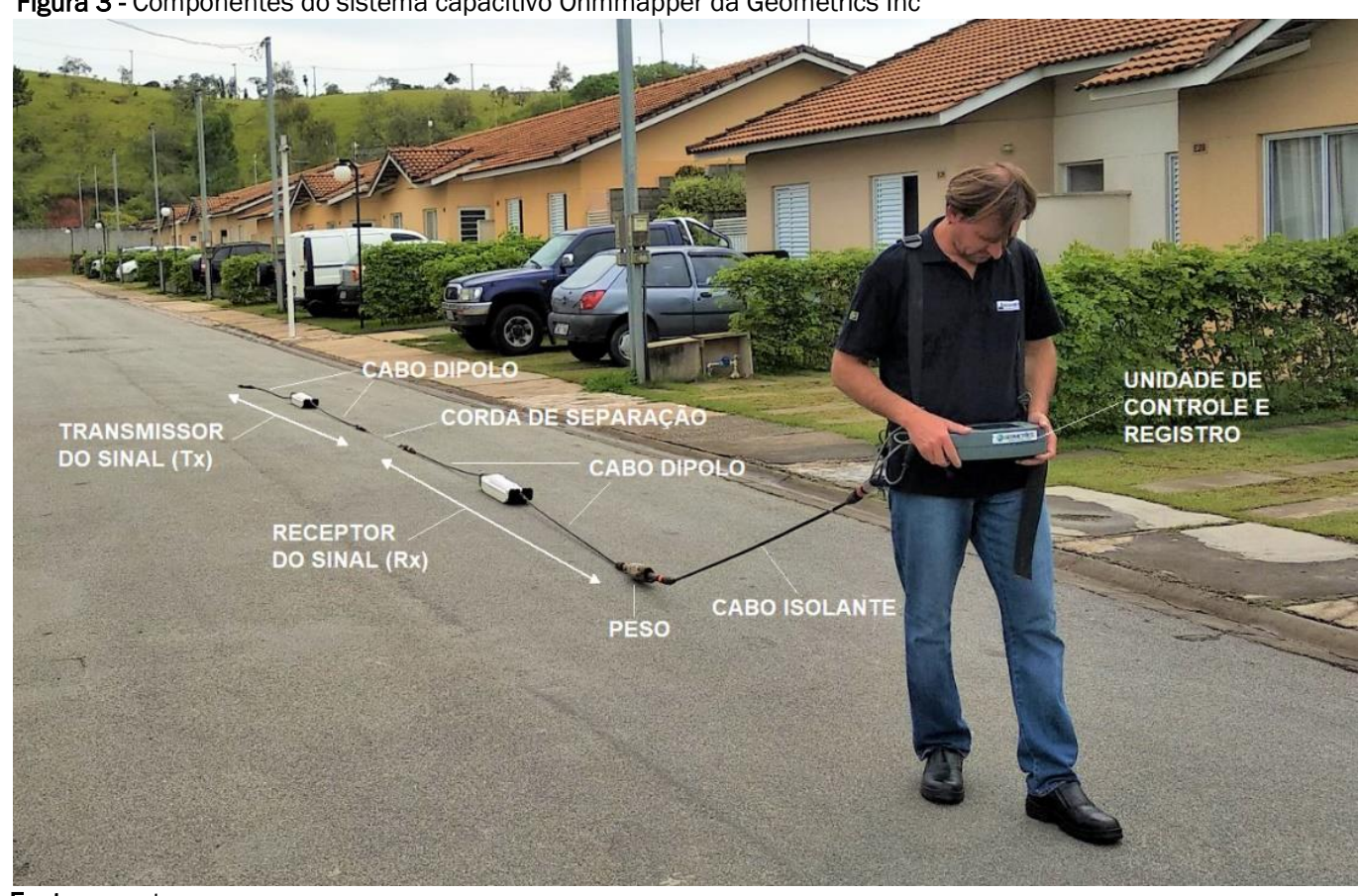

Fonte: os autores.

Este instrumento permite a aquisição de dados com separação padrão entre transmissor e receptor de 1,0, 5,0, 10,0 e 20,0 metros (default), podendo esses padrões de distâncias também serem alterados em seu sistema operacional. Contudo, na aquisição de dados utilizando um conjunto capacitivo com dois ou mais receptores de sinal, a necessidade de se realizar mais repetições no mesmo perfil diminui, sendo que, por exemplo, para três, quatro ou cinco receptores acoplados (Figura 5) apenas uma passagem já poderia ser suficiente para uma amostragem de dados com resolução satisfatória dependendo dos objetivos. 
Figura 4 - Diagrama do sistema monorreceptor de Resistividade Capacitiva

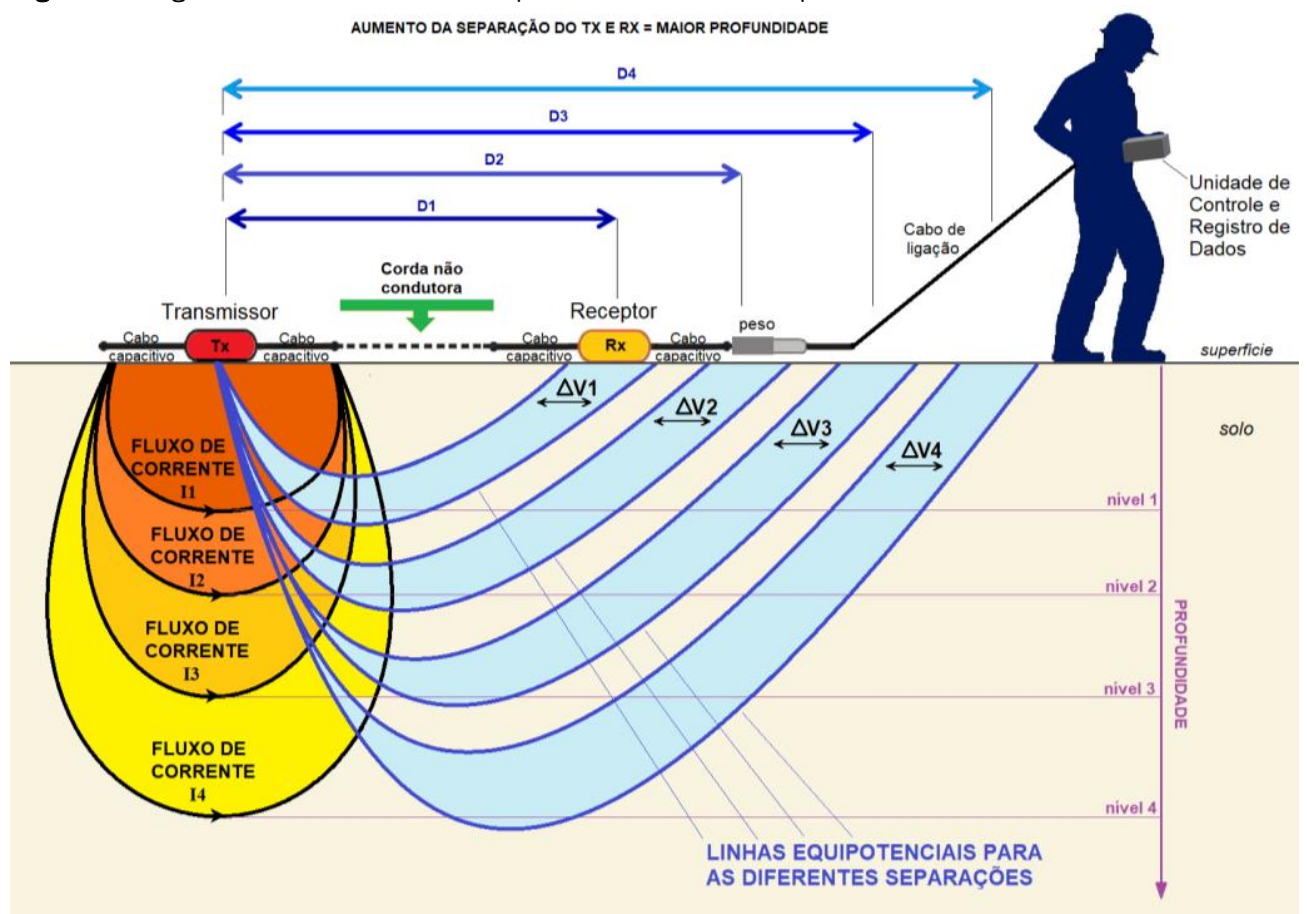

Fonte: modificado de Geometrics (2001).

Figura 5 - Diagrama do sistema multirreceptor de Resistividade Capacitiva

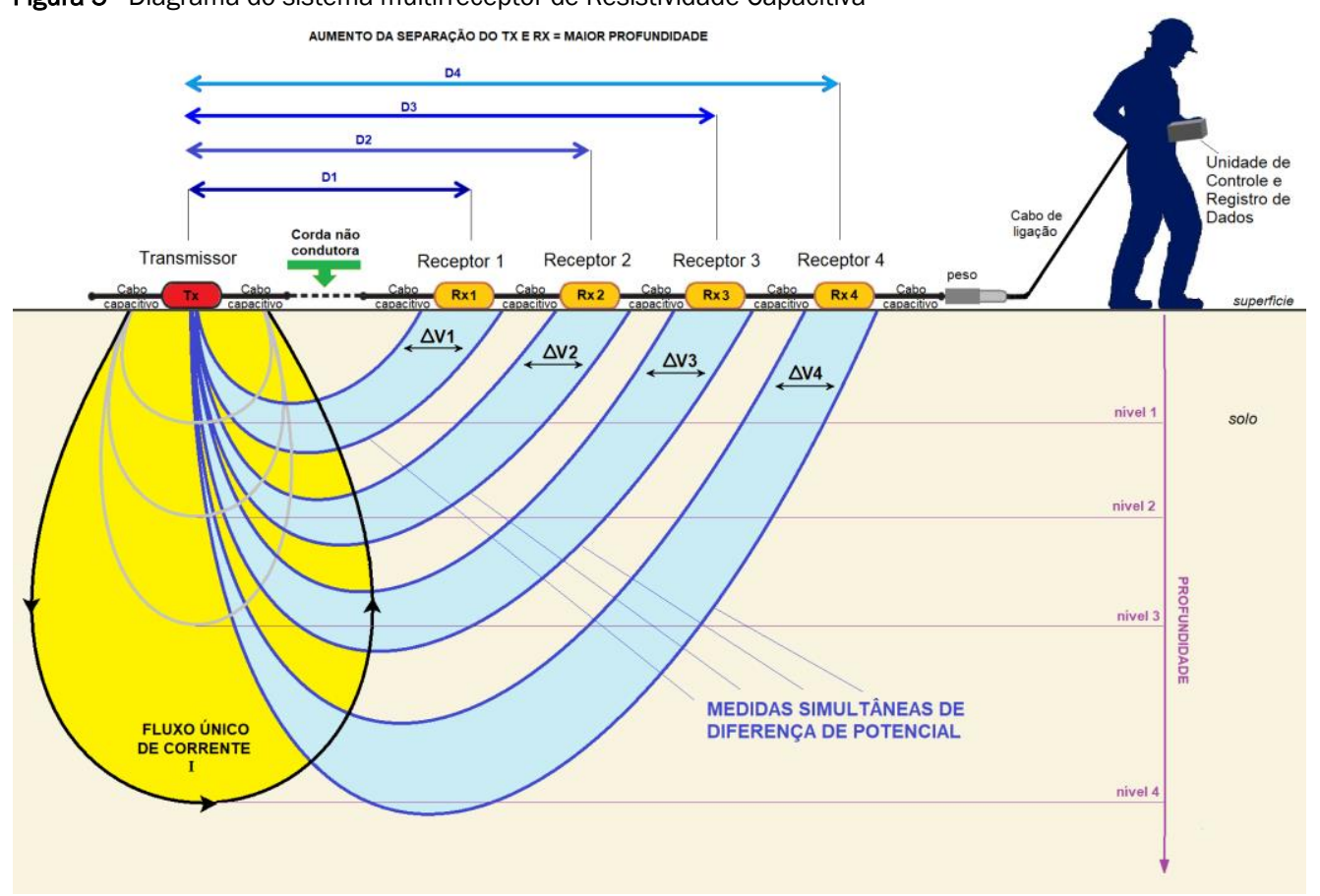

Fonte: modificado de Geometrics (2001).

De maneira geral, a profundidade de investigação de um determinado método geoelétrico depende de alguns fatores, dentre eles a potência ou capacidade da fonte elétrica e do equipamento utilizado, bem como da distância entre a fonte e os receptores e das propriedades elétricas do meio geológico, os quais, teoricamente, possibilitam para o sistema capacitivo Ohmmapper investigações entre 5,0 e 15,0 metros de profundidade máxima e que dependem da capacidade em 
que o sinal do transmissor pode ser detectado e decodificado pelo receptor (GEOMETRICS, 2001).

Dentre esses fatores, Kuras (2002) destaca a influência da resistividade elétrica do terreno na profundidade de alcance do método de Resistividade Capacitiva, onde, para uma determinada corrente elétrica, se a resistência do solo for alta (por exemplo solo arenoso), a tensão gerada também é alta, facilitando a propagação da corrente elétrica e as medições em níveis mais profundos. Por outro lado, se a resistência elétrica do solo for baixa (por exemplo meio argiloso), a tensão resultante será baixa, dificultando as medidas em maiores profundidades.

Desta maneira, em relação às variações de profundidades em função das resistividades elétricas do meio, o comportamento verificado no método de Resistividade Capacitiva é distinto do que ocorre com a Eletrorresistividade galvânica, apontando mais uma de suas diferenças, porém, é muito similar ao que é observado nos métodos geofísicos eletromagnéticos, em particular ao GPR.
Quanto à resolução, o equipamento Ohmmapper possibilita a amostragem de dados com grande detalhamento, pois permite a execução de medições contínuas ou com intervalos menores que 30 centímetros conforme a programação de tempo de disparo do sinal elétrico, além de resolução vertical da ordem de 1,0 m ou menos dependendo da separação entre transmissor e receptor (KURAS, 2002).

$\mathrm{Na}$ etapa de processamento, os dados oriundos dos perfis individuais de resistividade elétrica de diferentes profundidades de uma mesma linha de levantamento são agrupados e convertidos em resistividade aparente gerando, posteriormente, as pseudo-seções de resistividade elétrica através de programas de inversão e modelamento, passando-se, finalmente, a fase de interpretação dos resultados, como visto no exemplo da Figura 6 referente a uma seção realizada na faixa litorânea do município de Balneário Camboriú e onde sondagens indicaram a presença de aterro superficial sobreposto aos sedimentos predominantemente arenosos e nível d’água local variando entre 1,2 e 1,8 metros de profundidade.

Figura 6 - Pseudo-seção de Resistividade Capacitiva e feições geológicas interpretadas.

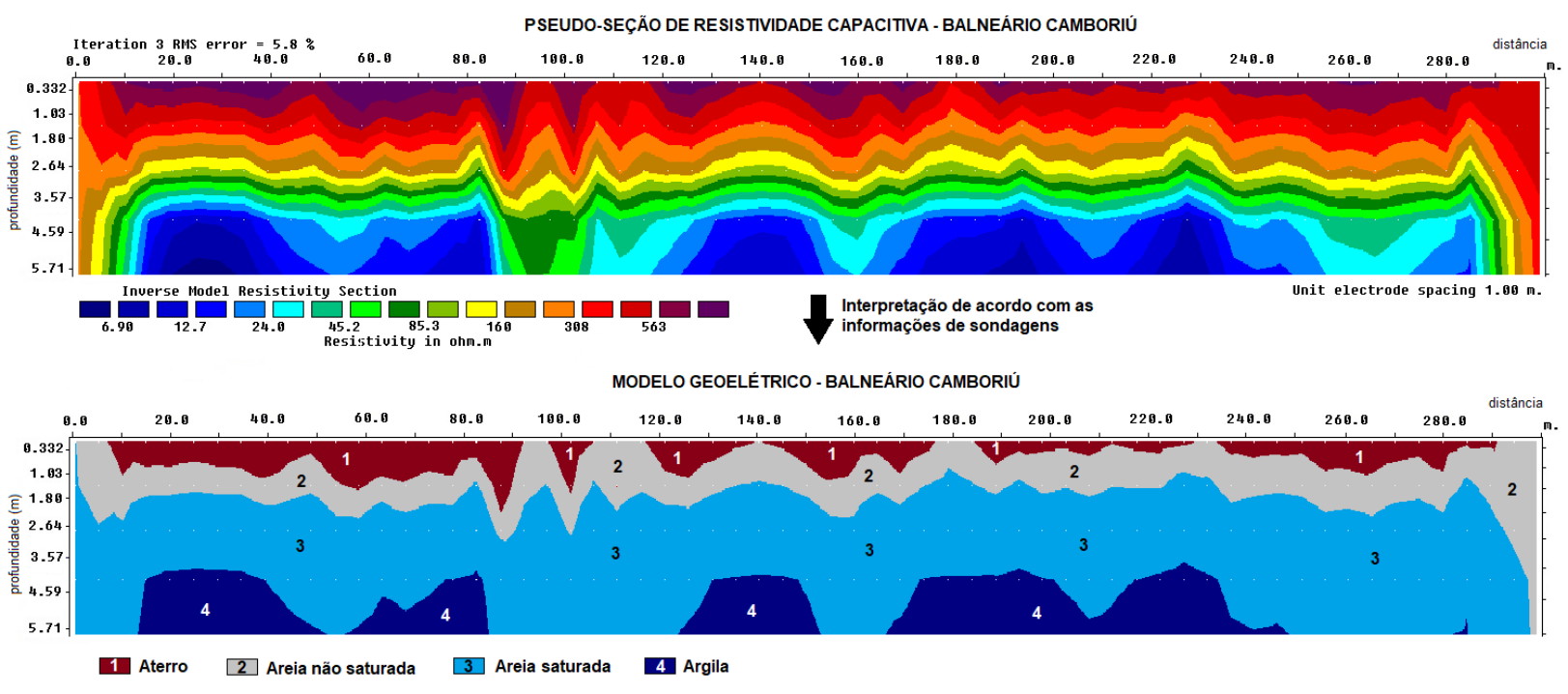

Fonte: os autores

\section{DISCUSSÃO SOBRE A CLASSIFICAÇÃO ATUAL DOS MÉTO- DOS GEOELÉTRICOS}

Ao se discutir a aplicação da Geofísica, uma questão importante surge quanto às diferentes terminologias relativas à definição conceitual de método, técnica e arranjo, cuja necessidade de uniformização foi abordada no importante trabalho de Braga (2006) e que propõe, especificamente, a classificação dos métodos geoelétricos aplicados aos estudos hidroge- ológicos, como pode ser observada na Figura 7, e que por muito tempo tem sido adotada para nortear os diversos trabalhos na área de aplicação dos métodos geofísicos para Geologia, Engenharia, Hidrogeologia, Meio Ambiente, entre outros, não sendo o objetivo deste autor abordar os outros três grupos maiores, que são o método gravimétrico, o magnético e o sísmico, nem os métodos geofísicos com medições em poços. 
Figura 7 - Classificação dos métodos geoelétricos de superfície

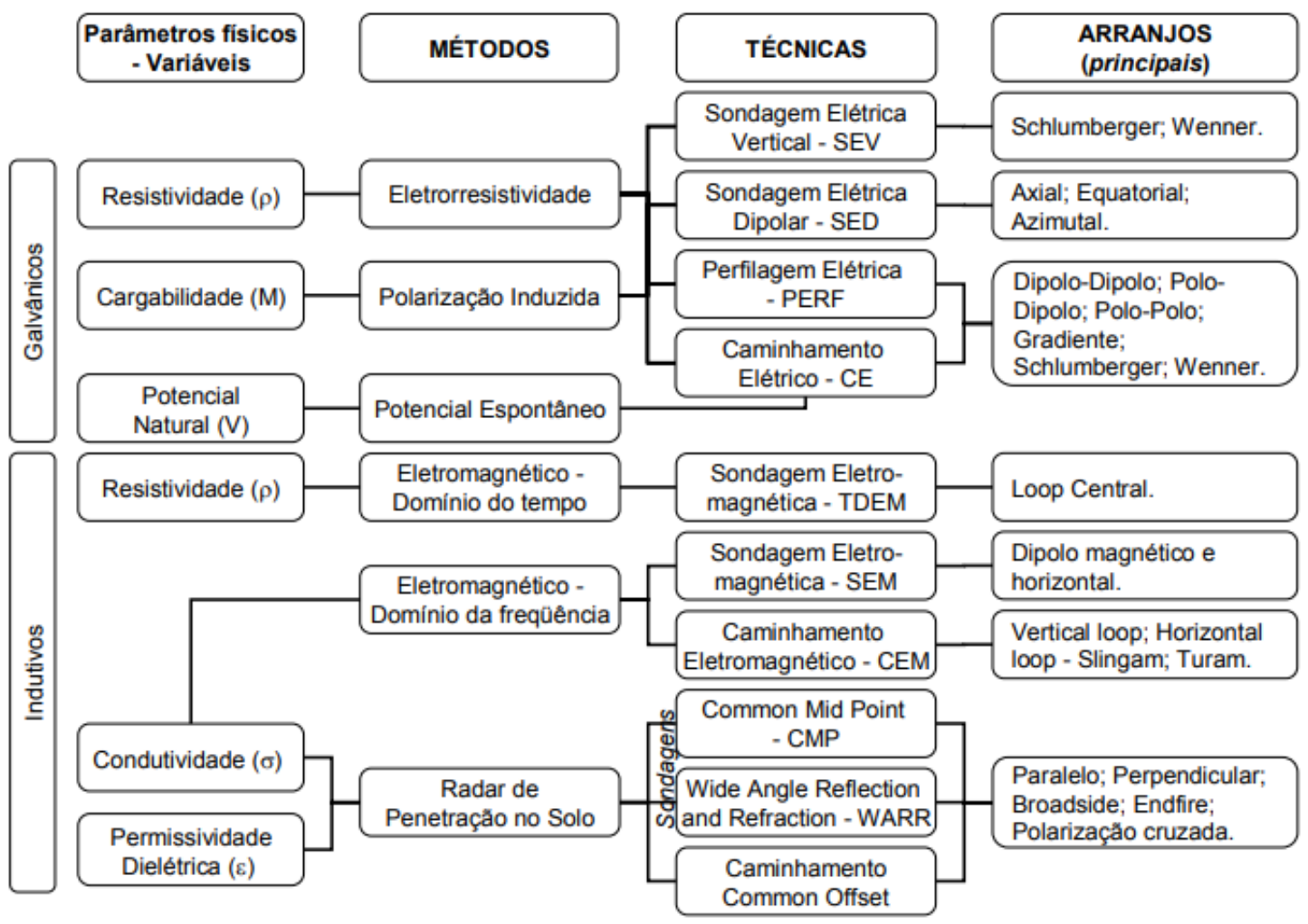

Fonte: Braga (2006).

Em publicações de orientação e divulgação da metodologia geofísica, a despeito de formalizações e distinções apresentadas por Braga (2006), os termos método e técnica, compreensivelmente, são empregados como sinônimos algumas vezes, como é o caso em certas descrições do Manual de Gerenciamento de Áreas Contaminadas da CETESB (2001), cujo público alvo é mais abrangente que apenas os de setores especializados da Geofísica, e é destinado ao entendimento de diferentes profissionais que atuam na área ambiental, tais como biólogos, químicos, gestores ambientais, engenheiros, geólogos, arquitetos e até advogados, entre outros.

Porém, quanto aos trabalhos acadêmicos voltados aos especialistas da área e onde há necessidade de clareza nas descrições metodológicas para reprodução do experimento ou pesquisa, reconhece-se aqui a necessidade de um maior rigor quanto às distinções de termos conforme preconizado pela classificação de Braga.

Neste contexto, como exemplo de adoção de sinonímia incorreta pode ser apontada a descrição que consta de artigo apresentado em Simpósio da Sociedade Brasileira de Geofísica (SBGf) quando se refere ao emprego de levantamentos elétricos e eletromagnéticos para detecção de contaminação subterrânea, no seguinte trecho:“...as técnicas geofísicas como Eletrorresistividade, Radar de Penetração no Solo (GPR) e Eletromagnético Indutivo (EM) são cada vez mais aplicadas na caracterização e monitoramento de áreas impactadas por contaminantes... (MINOZZO et al., 2009)", mas que trata-se de citar, na verdade, os métodos geofísicos.

Por outro lado, apesar do grande mérito da classificação dos métodos geoelétricos apresentada por Braga, esta necessita de reenquadramento para ser aberta às novas metodologias geofísicas já em uso e à inclusão de outras tecnologias que poderão vir a aparecer no futuro, bem como demanda revisões necessárias quanto a alguns conceitos para seu aperfeiçoamento.

Inicialmente, no que se refere à subdivisão dos métodos geoelétricos apenas em galvânicos e indutivos indicadas na classificação anterior da Figura 7, esta não mais se adequa e requer alterações em virtude do surgimento nos últimos anos de metodologias que combinam diferentes fontes de emissão do sinal geofísico, como é o caso do sistema de resistividade de matriz capacitiva descrito anteriormente, mas também, como exemplo, do equipamento com fonte indutiva e um receptor capacitivo proposto no trabalho de Adams de 2008.

Além disso, devem ser formuladas revisões conceituais e reclassificações no estabelecido por Braga (2006), por exemplo, no que se refere este autor ao método de GPR, ou Radar de Penetração no Solo, enquadrando-o ao grupo maior de métodos geoelétricos, inserindo-o ao subgrupo de métodos indutivos, e sendo indicadas a condutividade elétrica $(\sigma)$ e a per- 
missividade dielétrica $(\varepsilon)$ como parâmetros físicos medidos (variáveis).

Entretanto, diferentemente do que é indicado como parâmetros medidos, na metodologia GPR são efetuadas, na realidade, medições dos tempos de reflexão do sinal em subsuperfície, isto porque, na faixa de altas frequências de operação do GPR (de 10 a 2500 MHz), a propagação da onda eletromagnética em profundidade é similar ao de uma onda elástica (sísmica), sofrendo refração e reflexão, como descrito no trabalho de referência deste método elaborado por Davis \& Annan (1989).

Outro aspecto que necessita de alteração na classificação atual se relaciona à adoção de apenas os parâmetros físicos medidos para individualização de um determinado método geoelétrico. Porém, destaca-se aqui que um dos mais importantes fatores definidores, e que não é considerado, se refere ao tipo de fonte de emissão sinal, sendo que a combinação desses dois fatores seria ideal para a distinção do método geofísico, como será abordado mais a frente quando se discutir a classificação aqui proposta e a diferenciação entre os métodos de Resistividade Capacitiva e de Eletrorresistividade, já que ambos medem a mesma propriedade física que é a resistividade elétrica do terreno, entretanto com fontes de corrente elétrica distintas.

Ressalta-se, também, que a classificação de Braga para os métodos geoelétricos em aplicações hidrogeológicas não inclui o método VLF (Very Low Frequency) na categoria de métodos Eletromagnéticos, o qual se constitui numa metodologia geofísica importantíssima para a detecção de fraturas em rocha com finalidade de locação de pontos mais favoráveis à explotação de água subterrânea, como consta, por exemplo, do trabalho de Cordeiro \& Marinho (2000), principalmente, em áreas onde o manto de intemperismo é pouco espesso, devendo, portanto, ser inserido na reclassificação proposta.

Também corroborando com a necessidade de alterações, de maneira mais específica, pode ser citada a inserção da técnica de caminhamento eletromagnético para o método Eletromagnético no Domínio do Tempo (TDEM), além de mais arranjos do que os que constam na classificação ora vigente, como apresentado no trabalho de Bortolozo (2011).

Obedecendo uma tendência cada vez maior, há necessidade, também, de se considerar novos termos em função das denominações que vêm surgindo nos últimos anos por conta da automatização dos levantamentos de Eletrorresistividade através do emprego de diversos eletrodos simultaneamente (dispositivos multieletrodos), proporcionando maior rapidez e resolução dos dados, como por exemplo os sinônimos cada vez mais utilizados na literatura nacional, como também, pela comunidade geofísica internacional para a técnica de caminhamento elétrico que são tomografia de resistividade elétrica ou imageamento de subsuperfície (REYNOLDS, 2011), imageamento de resistividade 2D (GEMAIL et al., 2011), tomografia elétrica (KEAREY et al., 2013), imageamento elétrico (SILVA; MALAGUTTI FILHO, 2009) ou imageamento de resistividade elétrica (OSINOWO; FALUFOSI, 2018), além da designação não tão usual, e não tão correta, de sondagem elétrica vertical multieletrodos (SEV-ME), que aparece em alguns memoriais técnicos descritivos para levantamentos em faixas de dutos ou refinarias de petróleo aqui no Brasil, sendo aqui citada somente para efeitos de informação.

\section{RECLASSIFICAÇÃO DOS MÉTODOS GEOELÉTRICOS PARA HIDROGEOLOGIA E CONTAMINAÇÃO SUBTERRÂNEA}

Decorrente das discussões anteriores, é apresentada a seguir na Figura 8 uma reclassificação dos principais métodos geoelétricos, aplicados em superfície, tanto para estudos hidrogeológicos, como para diagnósticos da contaminação subterrânea, atualizando de uma forma mais abrangente o anteriormente estabelecido por Braga (2006), bem como obedecendo as características individuais de determinados métodos geofísicos conforme seus fatores de definição e as possibilidades de surgimento futuro de fontes inovativas de emissão do sinal geofísico.

Assim, aperfeiçoando-se as definições da classificação de Braga (2006) em relação às terminologias e suas distinções, considera-se na reclassificação proposta os seguintes conceitos quanto à metodologia geofísica:

- Método: metodologia individualizada pelos fatores de definição como função do parâmetro físico medido, ou obtido, e do tipo de fonte do sinal geofísico emitido (ex. método de GPR, método Eletromagnético Indutivo, método de Polarização Induzida, etc);

- Técnica: tipo de investigação em campo para aplicação do método geofísico, com medição horizontal e/ou medição vertical das propriedades físicas de subsuperfície (ex. caminhamentos ou imageamentos, sondagens geofísicas, perfis);

- Arranjo: disposição dos emissores e receptores do sinal geofísico no terreno para o desenvolvimento da técnica em campo (ex. dipolo-dipolo, polarização cruzada, dipolo magnético vertical, etc). 
Figura 8 - Reclassificação dos principais métodos geoelétricos de superfície para estudos hidrogeológicos e de contaminação subterrânea

GRUPO DOS

MÉTODOS GEOELÉTRICOS

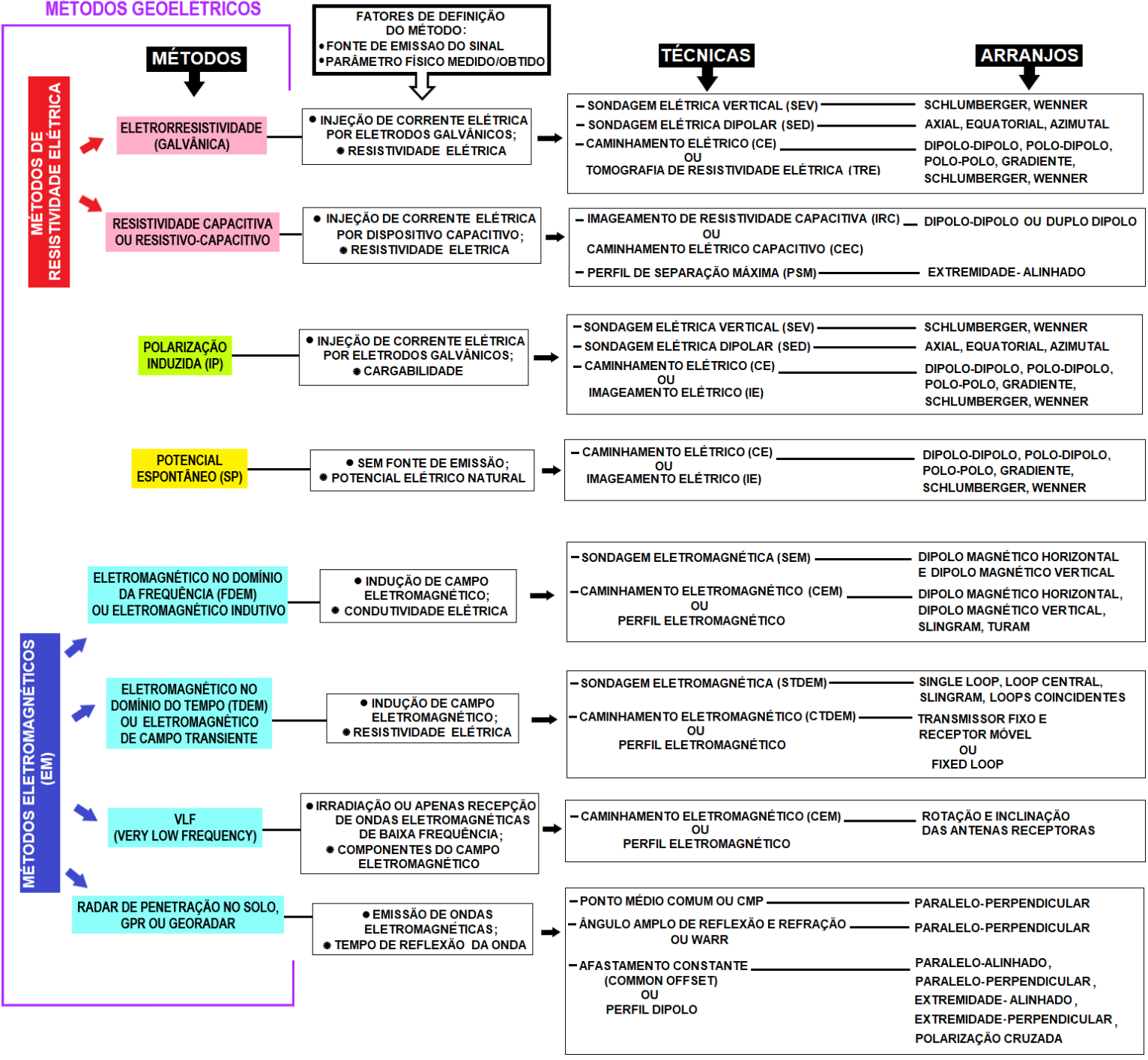

Fonte: os autores.

De maneira geral, nesta reclassificação da Figura 8, podem ser verificadas algumas modificações relativas à inclusão de método geofísico, de técnicas e arranjos de campo, inserção dos fatores de definição do método, adoção de termos atualizados e traduzidos para o português, além de sinônimos para certas técnicas e arranjos já empregados comumente, como também de ajustes conceituais e reposicionamentos.

Como exemplo de alteração, pode se citar o reposicionamento dos métodos de Resistividade Elétrica como um subgrupo dos métodos geoelétricos, sendo subdividido em método de Eletrorresistividade e método de Resistividade Capacitiva, o que possibilitou, portanto, a inclusão deste último nessa nova abordagem classificatória, um dos objetivos principais deste trabalho, e que na classificação original não seria possível.
Uma importante vantagem dessa nova forma de classificação menos hermética que a anterior é que permite a inclusão de tecnologias inovativas, tais como o já citado método proposto por Adams (2008) com fonte de emissão indutiva do sinal geofísico, representada pela geração de campo eletromagnético, e um receptor capacitivo para obtenção da resistividade elétrica do terreno. Neste caso, quando os instrumentos desta metodologia estiverem concluídos e disponíveis, esta poderia ser inserida nos métodos eletromagnéticos em função do tipo de emissão do sinal, e, decorrente de utilização de capacitor como receptor, denominada de método Eletromagnético-Capacitivo, ou Indutivo-Capacitivo, por exemplo.

Quanto à continuidade de designação do método de Eletrorresistividade nesta reclassificação ao se referir a metodologia mais tradicional de injeção de corrente elétrica contínua por 
contato (galvânico), salienta-se que tal denominação já está muito consolidada e aparece em inúmeros artigos ou publicações especializadas da área, não só de Geofísica Aplicada, como também de Geofísica Ambiental, tais como os trabalhos de Elis \& Zuquette (2002), Gallas et al. (2005) e Moreira et al. (2019), entre outros.

Portanto, como resultado das discussões anteriores, a metodologia geofísica apresentada neste artigo, que é o método de Resistividade Capacitiva, passa a ser a se diferenciar do método de Eletrorresistividade não em função do parâmetro físico obtido, que para ambas é a resistividade elétrica, mas sim do tipo de fonte de emissão do sinal para subsuperfície, sendo, para o primeiro, através de aparato capacitivo sobre a superfície do terreno e, para o segundo, por meio de eletrodos cravados no solo.

Assim, de acordo com as argumentações aqui expressas, o método geofísico de Resistividade Capacitiva (RC) se estabelece dentro do grande grupo dos métodos geoelétricos e do subgrupo de métodos de Resistividade Elétrica, sendo classificado como um método ativo, ou dinâmico, por ter uma corrente elétrica controlada (artificial) como fonte do sinal para o interior do terreno.

Referente à técnica de campo a ser aplicada na aquisição de dados pelo método de Resistividade Capacitiva, que consiste de medições horizontais com varredura lateral, esta será designada com o termo indicado por Kuras et al. (2007) e por Reynolds (2011) que é imageamento de resistividade capacitiva (IRC), do original capacitive resistivity imaging, e que, por analogia, poderia ser conhecida também por caminhamento elétrico capacitivo (CEC) ou caminhamento capacitivo (CC) de forma mais tradicional, ou ainda imageamento elétrico capacitivo (IEC) numa maneira mais inovativa.

\section{CONSIDERAÇÕES FINAIS}

O intuito da elaboração deste trabalho é divulgar e contribuir ao aprimoramento dos conceitos e à formalização das terminologias necessárias à orientação dos levantamentos da Geofísica Aplicada e Ambiental, tomando-se como base inicial a classificação anterior e que tem seus méritos por ter sido referência por longo tempo, mas que, atualmente, demandava modificações. Como resultado das discussões, foi apresentada uma reclassificação dos métodos geoelétricos, expandindo o campo atuação desta nova abordagem, não só apenas para a hidrogeologia, como também para os estudos ambientais de contaminação subterrânea, sendo inseridos novos métodos geofísicos, técnicas e arranjos, bem como traduções de alguns termos para a língua portuguesa e alterações necessárias conforme as argumentações aqui expressas. Destaca-se aqui que esta nova classificação determina como fatores definidores dois aspectos importantes para a distinção de um método geofísicos que são os parâmetros físicos medidos/obtidos e o tipo de fonte de emissão do sinal e que estabelecem sua individualização de forma consistente e, além disso, permite, também a inclusão de novas metodologias que poderão surgir com o avanço da tecnologia. Em relação ao método geofísico de Resistividade Capacitiva, a partir dos fundamentos da reclassificação aqui descritos, foi possível incluí-lo dentro das subdivisões dos métodos geoelétricos e definir os termos técnicos envolvidos na aplicação desta metodologia inovativa, o que na classificação anterior, da maneira como se estabelecia, não seria permitido. Ressalta-se, por fim, que a reclassificação aqui apresentada, à despeito das análises de caráter técnico que embasaram sua elaboração, também é aberta a outras contribuições que, por ventura, também possam vir aperfeiçoá-la.

\section{AGRADECIMENTOS}

Os autores agradecem à Coordenação de Aperfeiçoamento de Pessoal de Nível Superior (CAPES) pelo apoio a esta pesquisa.

\section{REFERÊNCIAS}

ADAMS, C.H. Capacitive array resistivity with an inductive source. Tese (Doutorado em Ciências Aplicadas). School of Applied Sciences. RMIT University. Melbourne, Austrália. 243p. 2008.

BORTOLOZO, C.A. Inversão conjunta $1 D$ de dados de SEV e TDEM: aplicações em hidrogeologia. Dissertação (Mestrado em Geofísica). Instituto de Astronomia, Geofísica e Ciências Atmosféricas. Universidade de São Paulo. 102p. 2011

BRAGA, A.C.O. Métodos de eletrorresistividade e polarização induzida aplicados nos estudos da captação e contaminação de águas subterrâneas: uma abordagem metodológica e prática. Rio Claro, 126p. Tese (Livre Docência em Geociências) Instituto de Geociências e Ciências Exatas, Universidade Estadual Paulista. 2006.

CARMONA, E.A.F.; BARBOSA, A.M.; USTRA A.; ELIS V.; MENDONÇA, C. Aplicação do método resistivo-capacitivo para investigação de uma área contaminada por creosoto. In: SIMPÓSIO BRASILEIRO DE GEOFÍSICA DA SOCIEDADE BRASILEIRA DE GEOFÍSICA (SBGf), 8., 2018. [Anais...]. Salinópolis - PA. 4 p. 2018. https://doi.org/10.22564/8simbgf2018.124

CAVENAGHI, V.L.S. Caracterização geoelétrica de alvos rasos no Sítio Controlado de Geofísica Rasa II - IAG-USP através de resistividade capacitiva. Dissertação (Mestrado em Geofísica). Instituto de Astronomia, Geofísica e Ciências Atmosféricas. Universidade de São Paulo. 148p. 2017.

CETESB - COMPANHIA AMBIENTAL DO ESTADO DE SÃO PAULO. Manual de gerenciamento de áreas contaminadas. Programa CETESB/GTZ. São Paulo. 389p. 2001.

CORDEIRO, W.; MARINHO, J.M.L. Aplicação hidrogeológica do método geofísico VLF (Very Low Frequency) em áreas de coberturas sedimentares cenozoicas do Ceará, Brasil. In: JOINT WORLD CONGRESS ON GROUNDWATER, 1., 2000. [Anais...] 
Fortaleza, CE: Associação Brasileira de Águas Subterrâneas (ABAS), 2000. 17p.

DAVIS, J.L.; ANNAN, A.P. Ground-penetrating radar for high resolution mapping of soil and rock stratigraphy. Geophysical Prospecting, v.37, n. 5, p 531-551, 1989. https://doi.org/10.1111/j.1365-2478.1989.tb02221.x

ELIS, V.R.; ZUQUETTE L.V. Caracterização geofísica de áreas utilizadas para disposição de resíduos sólido urbanos. Revista Brasileira de Geociências, v. 32, n. 1, p. 119-134, 2002. https://doi.org/10.25249/0375-7536.2002321119134

GALLAS, J.D.F.; TAIOLI, F.; SILVA, S.M.C.P.; COELHO, O.G.W.; PAIM, P.S.G. Contaminação por chorume e sua detecção por resistividade. Revista Brasileira de Geofísica, v. 23, n. 1, p. 5159, $2005 . \quad$ https://doi.org/10.1590/S0102$\underline{261 \times 2005000100005}$

GEMAIL, K.S.; EL-SHISHTAWY A.M.; EL-ALFY M.; GHONEIM M.F.; ABD EL-BARY M.H. Assessment of aquifer vulnerability to industrial waste water using resistivity measurements. A case study, along El-Gharbyia main drain, Nile Delta, Egypt. Journal of Applied Geophysics, v. 75, p 140-150, 2011. https://doi.org/10.1016/i.jappgeo.2011.06.026

GEOMETRICS INC. Manual de operação do equipamento OhmMapper TR1 29005-01. Rev.F, 2001. 147 p.

GREENHOUSE, J.P. Environmental geophysics: it's about time. Geophysics: The Leading Edge, v. 10, p. 32-34, 1991. https://doi.org/10.1190/1.1436775

KEAREY, P.; BROOKS, M.; HILL, I. Geofísica de exploração. Tradução Maria Cristina Moreira Coelho. $1^{a}$ Reimpressão. São Paulo: Oficina do Texto, 2013. 438 p.

KURAS, O. The capacitive resistivity technique for electrical imaging of the shallow subsurface. Tese (Doutorado em Ciências). Universidade de Nottingham. Inglaterra, 286p. 2002.

KURAS O.; MELDRUM P.I.; BEAMISH D.; OGILVY R.D.; LALA D. Capacitive resistivity imaging with towed arrays. Journal of Environmental and Engineering Geophysics, v. 12, p. 267-279, 2007. https://doi.org/10.2113/JEEG12.3.267

MINOZZO. M.; ELIS, V.R., USTRA, A.T.; MISSAKI. F. Aplicação de ensaios elétricos e eletromagnéticos em uma área industrial contaminada em São Paulo - Brasil - resultados prelimi- nares. In: CONGRESSO INTERNACIONAL DA SOCIEDADE BRASILEIRA DE GEOFÍSICA (SBGf), 11., 2009. [Anais...]. Salvador, Brasil, p. 24-28, 2009. https://doi.org/10.1190/sbgf2009121

MOREIRA, C.A.; BORTOLIN, J.R.M.; MALAGUTTI FILHO; W.; DOURADO, J.C. Alterations in electrical resistivity of sandy soil in controlled experiment by infiltration of stillage. Revista Geociências, v. 38, n. 1. p. 147-156, 2019. https://doi.org/10.5016/geociencias.v38i1.12697

OSINOWO 0.0.; FALUFOSI, M.O. 3D Electrical Resistivity Imaging (ERI) for subsurface evaluation in preengineering construction site investigation. Journal of Astronomy and Geophysics, $\begin{array}{llll}\text { v. } 7, \quad \text { p. } & 309-317,\end{array}$ https://doi.org/10.1016/j.nrjag.2018.07.001

PARASNIS, D.S. Principles of applied geophysics. 5 ed. London: Chapman \& Hall Editores, 1997. 429 p.

REYNOLDS, J.M. An introduction to applied and environmental geophysics. 2 ed. Oxford: Wiley-Blackwell Editores, 2011. 696 p.

SILVA, F.C. Avaliação de metais potencialmente tóxicos em zona não saturada da necrópole de Nossa Senhora Aparecida, Piedade, SP. Tese (Doutorado em Ciências Ambientais) Instituto de Ciência e Tecnologia de Sorocaba, Universidade Estadual Paulista, Sorocaba, 249p. 2018. https://doi.org/10.1590/S1413-41522009000300006

SILVA, R.W.C.; MALAGUTTI FILHO, W. O emprego de métodos geofísicos na fase de investigação confirmatória em cemitérios contaminados. Revista de Engenharia Sanitária e Ambiental, v. 14, n. 3. p. 327-336, 2009.

STEEPLES, D. Uses and techniques of environmental geophysics. Geophysics: The Leading Edge, v. 10, n. 9, p. 30-31, 1991. https://doi.org/10.1190/1.1436839

YAMASHITA, Y.; GROOM D.; INAZAKI T., HAYASHI K. Rapid near surface resistivity survey using the capacitively-coupled resistivity system: OhmMapper. In: INTERNATIONAL SYMPOSIUM OF SOCIETY OF EXPLORATION GEOPHYSICISTS OF JAPAN (SEGJ), 7., 2004. [Proceedings...]. Sendai, Japão. p. 292-295, 2004. 


\section{APÊNDICE}

Na reclassificação apresentada neste artigo para os métodos geoelétricos aplicados aos estudos hidrogeológicos e ambientais de contaminação subterrânea, muitas das terminologias correspondentes aos diferentes métodos, técnicas de levantamento e arranjos de campo são traduções de nomenclatu ras originais a partir da língua inglesa. Neste sentido, como forma de ilustrar e servir de referência a outras consultas, a seguir, pode ser observada esta nova classificação em sua versão em inglês e que no corpo do trabalho aparece na Figura 8.

Reclassification of the main geoelectric methods for hydrogeological and underground contamination studies

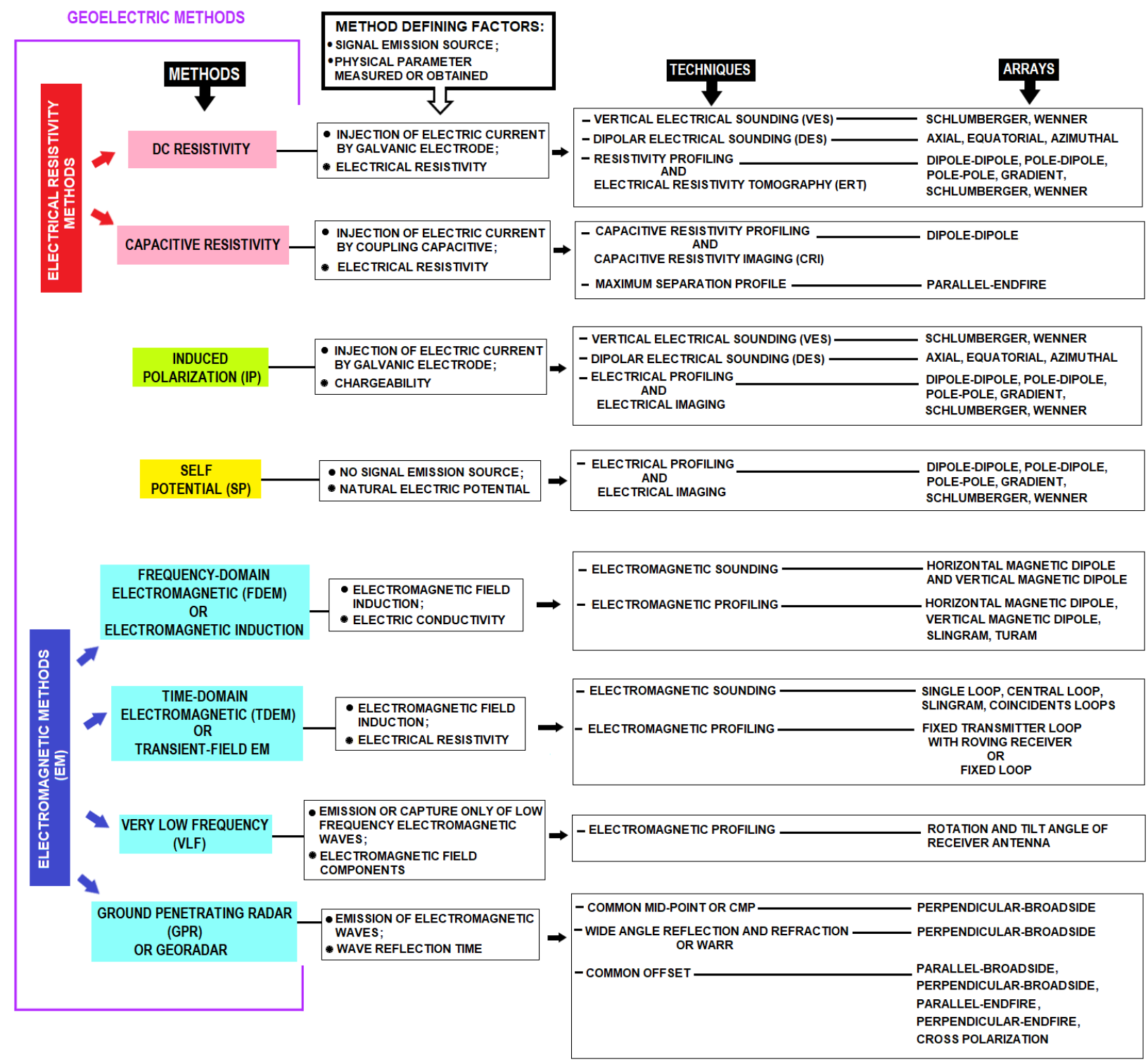

